\title{
Synaptic Reorganization Induced by Selective Photoablation of an Identified Neuron
}

\author{
Adi Mizrahi and Frederic Libersat \\ Zlotowski Center for Neuroscience and Department of Life Sciences, Ben-Gurion University of the Negev, Beer-Sheva, \\ 84105 Israel
}

\begin{abstract}
The maintenance of synaptic strength and specificity in the CNS may depend on interactions among postsynaptic dendrites. We examined the effect of removing a neuron on synaptic organization. A single identified postsynaptic neuron in the adult cercal system of the cockroach was removed with photoablation. After a 30 d recovery period, the synaptic connectivity and morphology of the intact presynaptic and postsynaptic neurons were analyzed. The synaptic connectivity was reorganized in a manner that was consistent with functional plasticity.

To associate anatomical changes with this reorganization, we analyzed the morphology of the presynaptic and postsynaptic
\end{abstract}

An important requirement for the establishment of functional neuronal networks is precise wiring of presynaptic and postsynaptic elements in the CNS. Once formed, neuronal networks remain plastic to adjust to changes in the environment (Kempermann et al., 1997; Nilsson et al., 1999; Young et al., 1999), acquire and store new information (Martin et al., 2000), and compensate for neuronal loss (Horner and Gage, 2000). The detailed sculpting of synaptic connections, their ability to proliferate and change, is retained for long periods of time, perhaps throughout life.

One well documented cellular mechanism by which neuronal wiring is regulated concerns competitive interactions among presynaptic axonal terminals. Axonal competition was initially demonstrated in the visual cortex (Wiesel and Hubel, 1963) and found to be a fundamental process in synaptic wiring of both central and peripheral synapses. Axonal competition takes place during wiring of the nervous systems of both invertebrates (Murphey and Lemere, 1984; Muller and Gu, 1991; Gan and Macagno, 1997) and vertebrates (Nguyen and Lichtman, 1996; Penn et al., 1998). Evidence for competition has been revealed primarily by the subtraction or addition of presynaptic elements, which induces functional reorganization of the presynaptic elements (for review, see Guillery, 1988). In this study, our goal was to determine whether removal of a postsynaptic element would also induce functional reorganization of a neuronal circuit, such as changes in

Received May 24, 2001; revised July 24, 2001; accepted July 27, 2001.

This work was supported by the Israel Academy of Sciences and Humanities (335/00-1). These experiments comply with Principles of Animal Care, National Institutes of Health publication no. 86-23, revised in 1985, and also with the current laws of the State of Israel. We thank Gustavo Glusman for technical assistance and Alain Hamon for generous help with setting up the electrophysiology of the single sensory afferent to giant interneuron synapse. We also thank R. B. Levine and J. C. Schaeffer for critically commenting on and improving this manuscript.

Correspondence should be addressed to Dr. Frederic Libersat, Department of Life Sciences, Ben-Gurion University of the Negev, P.O. Box 653, Beer Sheva, 84105 Israel. E-mail: libersat@bgumail.bgu.ac.il.

Copyright (ㄷ) 2001 Society for Neuroscience $\quad 0270-6474 / 01 / 219280-11 \$ 15.00 / 0$ neurons by quantitative morphometry. Both presynaptic and intact postsynaptic neurons maintained a stable morphology after removal of a neighboring postsynaptic neuron. Using the Hausdorff Match method (HM) (Mizrahi et al. 2000), we found that the spatial organization of the intact dendritic and axonal trees after ablation of a postsynaptic neuron remained stable. Thus, interactions with neighboring neurons were not necessary for maintaining dendritic morphology in the adult nervous system. However, adult central synapses were capable of adjusting to maintain normal function.

Key words: plasticity; photoablation; insect; dendrites; quantitative morphology; Hausdorf match

synaptic physiology and/or the structure of presynaptic and postsynaptic elements.

To address this question at the level of individual central synapses, it is useful to turn to a small circuit with a well defined connectivity and fairly invariant architecture. Thus, to study synaptic reorganization after removal of a postsynaptic element, we took advantage of the cercal system of the cockroach, Periplaneta americana, which allows the cockroach to escape from predators (Camhi, 1984; Ritzmann, 1984). The cercal circuit consists of a relatively small number of presynaptic and postsynaptic neurons that can be identified unequivocally (Daley et al., 1981; Camhi, 1984; Hamon et al., 1994). The pattern of synaptic connectivity and the functional properties of this circuit are well defined (Daley and Camhi, 1988; Camhi, 1989; Hamon et al., 1994; Kolton and Camhi, 1995; Levi and Camhi, 2000; Mizrahi et al., 2000). Furthermore, it is possible to ablate a single neuron using intracellular injections of pronase or a fluorescent dye (Comer, 1985; Comer et al., 1988; Libersat, 1989; Libersat and Mizrahi, 1996). Finally, the network is causally related to the stereotyped escape behavior and has served as a neuro-ethological model of synaptic plasticity (Volman and Camhi, 1988; Stern et al., 1997).

A preliminary report of this data has been published previously in abstract form (Mizrahi and Libersat, 2000).

\section{MATERIALS AND METHODS}

\section{Animals}

Male cockroaches (Periplaneta americana) from the laboratory colony were used in all experiments. Cockroaches were raised in plastic barrels, kept at $27-32^{\circ} \mathrm{C}$, and provided with water and cat chow ad libitum.

\section{In vivo photoablation and cell identification}

Freshly molted adults (within $48 \mathrm{hr}$ after the molt) were cooled $\left(2^{\circ} \mathrm{C}\right)$ and placed ventral side up on a Peltier device, and a flap was opened in the cuticle to expose the ventral nerve cord. A selected identified giant interneuron (GI) was killed using the photoablation technique (Miller and Selverston, 1979; Libersat and Mizrahi, 1996). A single identified GI 
was impaled in the axon between the A5 and A6 connectives and injected with $6 \%$ carboxyfluorescein for $10-15$ min using -10 nA DC. The GI was ablated in vivo using an Argon ion laser (480 nm) aimed at the last abdominal ganglion, which houses the cell body and dendritic tree of the GI. The laser spot was roughly $50 \mu \mathrm{m}$ in diameter and aimed at the cell body of the injected GI. To calibrate the cell photoablation procedure, the death of the GI was verified in two ways in a first series of 10 experiments. First, in all 10 experiments cell death was accompanied by a long-lasting burst of action potentials and a subsequent loss of the membrane potential within $20-40 \mathrm{sec}$ after illumination. In all subsequent experiments, injected GIs were illuminated for at least $3 \mathrm{~min}$ without recording the GI membrane potential. Second, at the end of each of the 10 experiments, the nerve cord was sectioned and the axonal profile of the missing GI was identified. After photoablation, a few crystals of penicillin and streptomycin were added to the hemolymph, and the cuticle was carefully sealed with histoacryl (Braun). Approximately $90 \%$ of the animals survived the surgery. Animals were allowed to recover for 25-30 d. Then, they were opened, and the nerve cord was dissected out and placed in a recording chamber for either in vitro electrophysiological recording or staining, or both, as described below.

If not stated otherwise, "controls" always refers to freshly molted adult cockroaches that were sham operated and allowed to recover for 25-30 d.

\section{In vitro electrophysiology}

After GI ablation and recovery period, animals were anesthetized, and a portion of the nerve cord, which includes the cercal system, was removed for in vitro recordings. The preparation, which included the cerci and the abdominal portion of the nerve cord from A6 to A1, was dissected out and pinned on a Sylgard-coated dish (Dow Corning). The last abdominal ganglion was desheathed to access GI somata. Preparations were superfused continuously with saline composed of (in mm/l): $214 \mathrm{NaCl}, 3.1$ $\mathrm{KCl}, 9 \mathrm{CaCl}_{2}, 50$ sucrose, $10 \mathrm{TES}, \mathrm{pH} 7.2$, at room temperature. The contralateral cercal nerve was crushed to avoid input to the GIs originating from the contralateral cercus. The cercus was kept dry by isolating it from the nerves and ganglia in a well of Vaseline. To prevent hypoxia, oxygen was blown directly onto the cercus as described in Hamon et al. (1988). A single sensory neuron (from column h on segments 3, 4, or 5) was recorded by placing a broken microelectrode on the cut hair shaft. The electrode was connected to a piezzo-electric device to generate fine mechanical movements of the hair. The intensity and duration of the stimulation were set to induce a single action potential recorded with extracellular electrodes placed on the cercal nerve. A single GI was recorded in the soma using a glass microelectrode filled with $1 \mathrm{M} \mathrm{KCl} \mathrm{(tip}$ resistance $20-40 \mathrm{M} \Omega$ ). Synaptic strength was evaluated by the maximum amplitude of the unitary EPSP, which was calculated from at least 10 trials from each hair. All electrophysiological data were recorded and analyzed off-line using a custom-made data analysis program.

\section{Staining and reconstruction of sensory neurons}

The preparation, which included the cerci and the abdominal portion of the nerve cord from A6 to A1, was dissected out and pinned on a Sylgard dish. The cerci were isolated with Vaseline and kept dry while the nerve cord was rinsed thoroughly with saline. A single hair from column $\mathrm{h}$ on segment $4\left(\mathrm{~h}_{4}\right)$ was pulled out of its socket with a broken microelectrode, and a small Vaseline well was built around the socket. The sensory neuron was stained by adding a drop of $5 \%$ dextran-biotin into the well. The tissue was incubated for $48 \mathrm{hr}$ at $4^{\circ} \mathrm{C}$ to allow the dye to diff use throughout the axon. Then, the ganglion was desheathed, fixed in $4 \%$ paraformaldehyde for $3 \mathrm{hr}$, and incubated overnight with tritonated Millonig's buffer (MB) containing 5\% normal goat serum and $2 \mu \mathrm{g} / \mathrm{ml}$ avidin-Cy3. The tissue was dehydrated, cleared in methylsalicylate, and mounted onto a microscopic slide with Permount (Fisher Scientific, Houston, TX). This staining procedure was successful in $\sim 25 \%$ of the preparations.

The axon terminals of the $\mathrm{h}_{4}$ afferent were scanned with a laser scanning confocal microscope (Zeiss LSM510) with a $40 \times$ oil objective (Zeiss Plan Neofluor; NA $=1.31$ ). To cover the entire axonal terminal (which spans roughly $500 \mu \mathrm{m}$ in the $y$-axis), two to three different fields in the $x$-and $y$-axis were scanned to generate separate image stacks. Scans were made at 1024 pixel resolution without averaging and taken in $1 \mu \mathrm{m}$ steps (with $0.1 \mu \mathrm{m}$ overlap in the $z$-axis between images). Image stacks were converted into TIFF format, and the afferents were reconstructed with Neurolucida confocal software (Microbrightfield Ltd.).

\section{Staining and three-dimensional reconstruction of GIs}

GI staining and three-dimensional (3D) reconstruction have been described in detail in Mizrahi et al. (2000). Briefly, GIs were impaled either in the axon (between the A5 and A6 connectives) or in the soma with a glass microelectrode (tip resistance 20-40 $\mathrm{M} \Omega$ ) and filled with $2 \%$ neurobiotin in $1 \mathrm{M} \mathrm{KCl}$ for 30-60 min, followed by a diffusion period of $1 \mathrm{hr}$. The abdominal nerve cord was fixed in $2.5 \%$ gluteraldehyde in MB, $\mathrm{pH}$ 7.4, dehydrated, transferred to propylenoxide, and then rehydrated into MB. The ganglion was then incubated in collagenase/dispase (1 $\mathrm{mg} / \mathrm{ml}$ ) in $\mathrm{MB}$ at $37^{\circ} \mathrm{C}$ for $1 \mathrm{hr}$ and incubated overnight in avidinconjugated horseradish peroxidase (HRP) (Vectastatin elite ABC kit) diluted in tritonated MB. Subsequently, the tissue was processed with DAB and mounted with Permount. Each neuron was visualized through a BH-2 Olympus microscope with an immersion oil lens (100×; NA 0.8; working distance $0.66 \mathrm{~mm}$ ). Neurons were reconstructed in 3D using Neurolucida (Microbrightfield Ltd.). Only neurons filled to the tip of the finest distal dendrites were reconstructed. We also reconstructed the fiducials of the ganglion that houses the GIs for GI alignment as described below.

Axonal back-fills were performed by dissecting out part of the abdominal nerve cord (from ganglion A6 to A3). A single connective (between A5 and A6) was cut with sharp scissors and bathed in $0.2 \%$ neurobiotin for $48 \mathrm{hr}$ at $4^{\circ} \mathrm{C}$. Ganglia were then processed in the same way as for single GI staining.

\section{Alignment and scaling}

The alignment of the GIs was performed in three steps using the Neurolucida software: (1) GI rotation, (2) GI alignment, and (3) GI-GI alignment.

Step 1 (GI rotation). All the GIs were rotated according to a method described in Jacobs and Nevin (1991). Briefly, the fiducials of each ganglion containing a stained neuron were reconstructed at a low magnification $(20 \times)$. Because the ganglion has an elliptic shape, we were able to calculate the three axes from these fiducials (left-right, $x$-axis; anterior-posterior, $y$-axis; ventral-dorsal, $z$-axis). Each reconstruction was rotated independently on the basis of these three axes into a straight (parallel) axial set.

Step 2 (GI alignment). Each GI shows a common morphological feature, which is the junction between the link segment, the axon, and the main dendritic tree. We refer to this feature as the "alignment node" (AN). All GIs were aligned at their AN (Mizrahi et al., 2000).

Step 3 (GI-GI alignment). GIs were aligned separately in the 3D ganglionic space. The distance between the alignment nodes of $\mathrm{GI}_{1}$ and $\mathrm{GI}_{2}$ was calculated from axonal back-fills of the GIs within the same ganglion. In back-filled ganglia we could locate ANs of all the GIs. We determined the $\mathrm{AN}$ of $\mathrm{GI}_{1}$ as the reference point and calculated the vector from $\mathrm{AN}$ of $\mathrm{GI}_{1}$ to the $\mathrm{AN}$ of $\mathrm{GI}_{2}$ ( $n=7$ back-filled ganglia). Seven such vectors (distance and direction) between the AN of $\mathrm{GI}_{1}$ to the $\mathrm{AN}$ of $\mathrm{GI}_{2}$ were calculated from each backfill. The seven vectors were averaged, and this average vector was used as the template for GI-GI alignment. All $\mathrm{GI}_{1} \mathrm{~s}$ were aligned to the coordinates $0,0,0$. The $\mathrm{GI}_{2} \mathrm{~s}$ were aligned to the distance and direction of the average vector.

Sensory neurons were aligned in a similar way as the GIs with the following differences. In step 2, an identified morphological point on the primary axon was used instead of the AN of the GIs. In step 3 we used double-staining preparations of a single sensory axon (using dextran biotin-Cy5) and back-filled GIs (using dextran-tetramethylrhodamine) ( $n=3$ ganglia).

The size of ganglia varies $10-20 \%$ between different animals. Because we did not find any correlation between any given morphometric parameter and ganglion size, we did not rescale the neurons.

\section{Morphometric analysis}

GIs and sensory neurons were examined quantitatively by using classical morphometric parameters such as number of branch points, total length, total surface area, total volume, and fractal dimension (box-counting method). These measures were calculated by the Neuroexplorer software (Microbrightfield Ltd.). Topological comparisons were performed by calculating the "tree asymmetry" for branched trees (Van Pelt et al., 1992). The topological structure of a tree is characterized by the number of its segments and the branching pattern of the segments. Some neurons such as the GIs that reach as many as $25-30$ branch orders have many possible tree types. To evaluate changes in tree topology we used the measure of tree asymmetry (Van Pelt et al., 1992). Tree asymmetry is the 
mean value of partition asymmetries in the tree. The asymmetry value equals zero when at each bifurcation the two sub-trees in the pair have an equal number of terminal segments (maximal symmetry). It approaches value 1 when one of the two sub-trees consists of one terminal segment (maximal asymmetry).

In addition, we used the HM method to analyze the spatial organization of dendritic and axonal trees. The HM method was described in detail in Mizrahi et al. (2000). Briefly, the HM is a pairwise comparison that provides a value of "percentage of overlap" between two trees as a function of increasing tolerance levels $(\epsilon)$. The HM measures the percentage of inclusion of one tree within the other. After aligning two trees, we take the 3D bounding box that includes the two trees and divide it into "voxels" of $2 \mu \mathrm{m}^{3}$ to create a 3D grid within the bounding box. Then, each branch of each tree is converted into a set of points that fills the branch volume. All HM comparisons use such sets of points as their input files.

Given two sets of points, "set A" and "set B" each representing a tree, for each point in set $A$ we search for a point in set B at distance $\epsilon$. Similarly, at distance $\epsilon$, for each point in set B we search for a point in set $A$. The percentage of points in set $A$ that have a match in set $B$ is the one-way HM from set A to set B. We calculate this value for different $\epsilon$ and construct a graph of "percentage of match" for different $\epsilon$. In the same way we build the graph for the one-way HM from set B to set A. In Figure 7 the HM analysis represents the one-way HM curve that is based on the lower HM values. In Figure 8 the HM analysis of Figure 8 represents the one-way HM between the indicated trees.

The HM analysis was performed between aligned dendritic/axonal trees and calculates all possible rotational combinations (in \pm 7 degrees in all axes).

\section{Paraffin sections}

The anterior portion of the cord (from A3 to A1) was fixed in 2.5\% gluteraldehyde, dehydrated, and transferred into propylenoxide for 30 min. Then, it was embedded in $50 \%$ paraformaldehyde $/ 50 \%$ Araldite [composed of $53 \%$ Araldite 502 Resin, $46 \%$ dodecenyl succinic anhydride, $1 \%$ 2,4,6-Tris (dimethylaminomethyl) phenol mixture] for $1 \mathrm{hr}$ and polymerized in Araldite for $18 \mathrm{hr}$ at $60^{\circ} \mathrm{C}$. Ganglia were serially sectioned $(3 \mu \mathrm{m})$ along the posterior-anterior axis with a microtome. Sections were collected onto a microscope slide and stained with $1 \%$ Toluidine blue. These were then photomicrographed through a compound light microscope (Olympus $\mathrm{BH} 2$ ) equipped with a digital camera using a $10 \times$ objective.

\section{Statistical analysis}

For the analysis of electrophysiological and morphological differences between the control and the experimental groups we used a student $t$ test. ANCOVA was used for spatial analysis of the HM method, using the tolerance level $(\epsilon)$ as the covariant. All ANCOVAs were performed after determining that both curves obeyed the general linear model. Throughout the paper, significances were accepted at $p=0.05$.

\section{RESULTS}

The first step of the experiment was to selectively ablate in vivo a single GI (either $\mathrm{GI}_{2}$ or $\mathrm{GI}_{3}$ ). Ablation was performed by the laser photoablation technique (Fig. $1 A$ ) and verified twice: first, during the ablation, by monitoring the loss of membrane potential (Fig. $1 A$, inset), and second, by comparing the axonal profiles of the intact and ablated sides of the ventral nerve cord (Fig. 1B). Identity of the ablated GI was verified by visualizing the filled neuron during the laser illumination or in the nerve cord profiles retrospectively (Fig. 1B).

\section{Physiology of identified synapses between sensory neurons and Gls}

In the adult, there are 220 filiform hairs on each cercus. Each cercus is divided into 19 segments numbered 1-19 from the base to the tip of the cercus. Each segment (2-13) bears a row of 14 hairs, each innervated by a single neuron. The hairs are arranged in longitudinal columns along the main axis of the cercus (Camhi, 1984). All sensory neurons of a given column have the same best wind direction. A GI receives input from several columns with
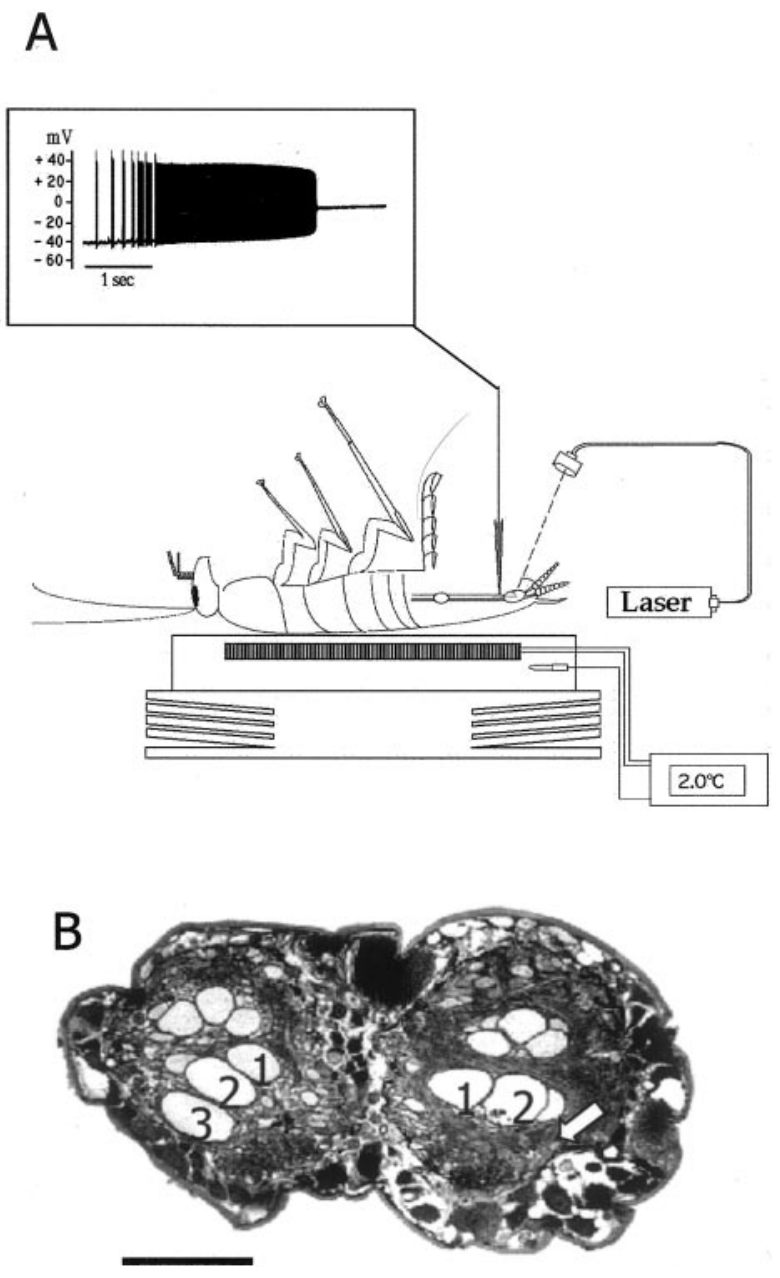

Figure 1. The photoablation procedure. A, Drawing of a cockroach placed ventral side up and anesthetized by cooling on a Peltier device. A cuticle flap was opened to access the ventral nerve cord for intracellular recording and ionophoresis of carboxyfluorescein. Inset, Laser illumination induced a tonic burst of action potentials and subsequent loss of membrane potential [modified from Libersat and Mizrahi (1996)]. B, A paraffin section of the ventral nerve cord of a $\mathrm{GI}_{3}$-ablated animal showing the axonal profiles of the GIs (numbers indicate the axons of $\mathrm{GI}_{1}, \mathrm{GI}_{2}$, and $\mathrm{GI}_{3}$, respectively); the arrow indicates the position of the missing axonal profile of right $\mathrm{GI}_{3}$. Scale bar, $100 \mu \mathrm{m}$.

different synaptic strength, the sum of which represents the receptive field of the GI (Daley and Camhi, 1988; Hamon et al., 1994). We quantified the synaptic strength of sensory neurons from cercal columns $\mathrm{d}$ and $\mathrm{h}$ to a GI by stimulating a single sensory afferent to fire a single action potential and recorded the evoked EPSP in the soma of $\mathrm{GI}_{1}$ (Fig. $2 A$ ). We chose to examine the synapses between columns $\mathrm{d}$ and $\mathrm{h}$ to $\mathrm{GI}_{1}$ because they show best directional sensitivity for front and back wind, respectively (Fig. 2B). In addition, column h contributes significantly to the wind receptive field of $\mathrm{GI}_{2}$, and column d contributes significantly to the wind receptive field of $\mathrm{GI}_{3}$ (Daley and Camhi, 1988; Hamon et al., 1994). These two columns contribute significantly to the front and back wind receptive field of $\mathrm{GI}_{1}$ (Fig. $2 B$ ) (Kolton and Camhi, 1995).

A deflection of a single $\mathrm{h}$ hair evokes a single action potential in the axon of the h neuron, which in turn evokes a unitary EPSP in $\mathrm{GI}_{1}$. The unitary EPSP is characterized by a short latency, a sharp rise time, and a slow decay time lasting for a few millisec- 

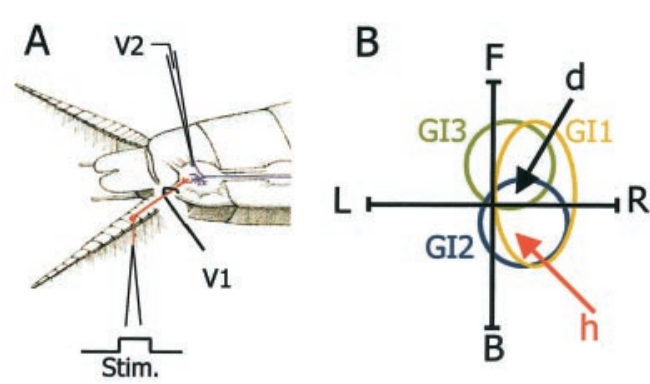

$$
\text { C }
$$

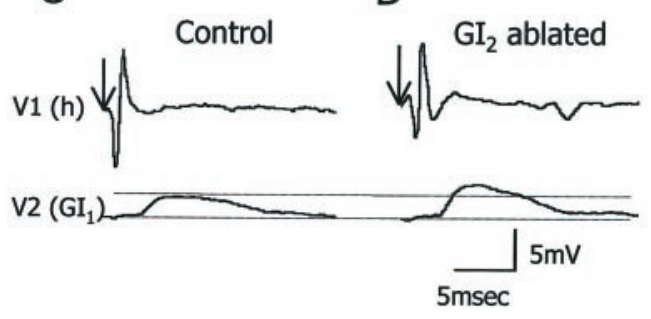

A
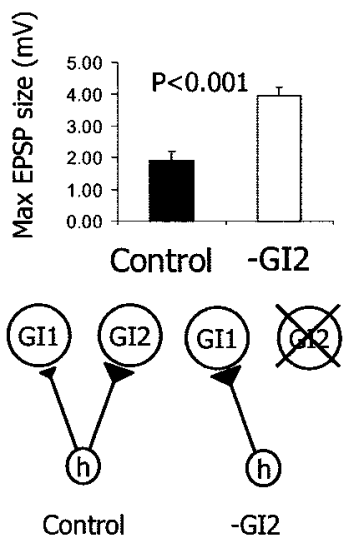

C
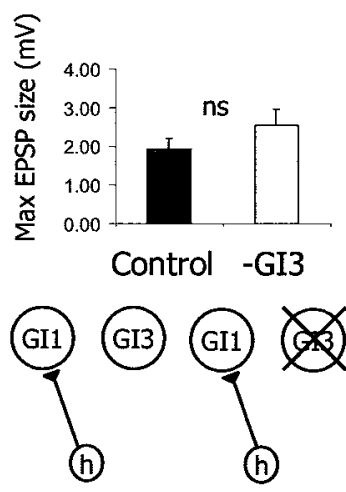

Control
Figure 2. Synaptic physiology of identified synapses. $A$, The recording configuration: $V 1$ shows the electrode for recording the sensory afferent axon, and $V 2$ is for recording the postsynaptic giant interneuron. $B$, Schematic representation of the wind receptive fields of $\mathrm{GI}_{1}, \mathrm{GI}_{2}$, and $\mathrm{GI}_{3}$ (polar traces) and best wind directions of afferents $\mathrm{d}$ and $\mathrm{h}$ (arrows). $C, D$, Unitary EPSP recordings of the $\mathrm{h}$ to $\mathrm{GI}_{1}$ synapse from a control $(C)$ and a $\mathrm{GI}_{2}$-ablated animal $(D)$. Arrows indicate the onset of stimulation of the $\mathrm{h}$ hair.

onds. An example recording from a control animal is shown in Figure $2 C$. For comparison, we sampled the same synapse (h to $\mathrm{GI}_{1}$ ) in animals $30 \mathrm{~d}$ after ablating $\mathrm{GI}_{2}$ (Fig. $2 D$ ). In animals in which $\mathrm{GI}_{2}$ had been ablated $(n=5)$, the maximal EPSP amplitude in $\mathrm{GI}_{1}$ increased significantly by $105 \%$ as compared with the controls $(n=5)$ (Fig. $3 A)(t$ test; $p<0.001)$. In addition we tested the $\mathrm{d}$ to $\mathrm{GI}_{1}$ synapse after ablation of $\mathrm{GI}_{2}$. After $\mathrm{GI}_{2}$ removal, back wind information is most affected. Because d column neurons code for front wind (Fig. $2 B$ ), we expected little change in the strength of the synapse from $\mathrm{d}$ to $\mathrm{GI}_{1}$ in $\mathrm{GI}_{2}$-ablated animals. In fact, in these animals $(n=5)$ the maximum EPSP amplitude of $\mathrm{d}$ to $\mathrm{GI}_{1}$ synapse decreased significantly by $35 \%$ as compared with the controls $(n=5)$ (Fig. $3 B)(t$ test; $p=0.05)$.

The ablation of a postsynaptic neuron affected synaptic strength only for those sensory neurons that are normally presynaptic to it. In contrast to $\mathrm{GI}_{2}$, the receptive field of $\mathrm{GI}_{3} \mathrm{~s}$ represents front wind (Fig. 2B). The $\mathrm{h}$ afferents do not establish synapses with $\mathrm{GI}_{3}$ (Hamon et al., 1994). In the $\mathrm{GI}_{3}$-ablated animals $(n=5)$, the maximal EPSP size of the $\mathrm{h}$ to $\mathrm{GI}_{1}$ synapse did not change (Fig. $3 C$ ) ( $t$ test; $p>0.05$ ). On the other hand, column d afferents synapse on both $\mathrm{GI}_{2}$ and $\mathrm{GI}_{3}$. Consistent with the specificity of synaptic changes, the maximal EPSP amplitude of the d to $\mathrm{GI}_{1}$ synapse significantly increased by $48 \%$ in the $\mathrm{GI}_{3}$-ablated animals $(n=5)$ as compared with the controls $(n=5)$ (Fig. 3D) $(t$ test; $p<0.05)$.

\section{Morphology of the presynaptic sensory afferents and the postsynaptic Gls}

To analyze the possible changes in neuronal structure, we stained and reconstructed column h sensory afferents from the control animals and the $\mathrm{GI}_{2}$-ablated animals. Likewise, we stained and reconstructed dendritic trees of $\mathrm{GI}_{1}$ from the control and the $\mathrm{GI}_{2}$-ablated animals. To evaluate possible changes in the neuronal morphology, we quantified the total membrane surface area,
Figure 3. Synaptic reorganization after single cell ablation. $A, B$, Histograms of the average EPSP amplitude evoked in $\mathrm{GI}_{1}$ in control animals $(n=5)$ and in $\mathrm{GI}_{2}$-ablated animals $(n=5)$. $A$, After $\mathrm{GI}_{2}$ ablation, the $\mathrm{h}$ to $\mathrm{GI}_{1}$ EPSP amplitude increased by $105 \%(t$ test; $p<0.001)$. $B$, After $\mathrm{GI}_{2}$ ablation, the $\mathrm{d}$ to $\mathrm{GI}_{1}$ EPSP amplitude decreased by $35 \%$ ( $t$ test; $p=0.05$ ). $C, D$, Histograms of the average EPSP amplitude evoked in $\mathrm{GI}_{1}$ in control animals $(n=5)$ and in $\mathrm{GI}_{3}$-ablated animals $(n=5)$. $C$, After $\mathrm{GI}_{3}$ ablation, the $\mathrm{h}$ to $\mathrm{GI}_{1}$ EPSP amplitude did not change significantly $(t$ test; $p>0.05)$. $D$, After $\mathrm{GI}_{3}$ ablation, the d to $\mathrm{GI}_{1}$ EPSP amplitude increased by $48 \%(t$ test; $p<0.05)$. A schematic drawing of the relevant elements of the synaptic circuitry in the control and the experimental condition is presented below each histogram.

number of branch points, total length, total volume, tree asymmetry, and fractal dimension of the axonal and dendritic trees.

\section{Presynaptic sensory terminals of $h_{\mathbf{4}}$}

In the literature, the axon terminals of the sensory afferents in adult cockroaches have already been described qualitatively (Volman, 1989; Hamon et al., 1994). Here we provide a quantitative analysis of the $\mathrm{h}_{4}$ afferent based on three-dimensional reconstruction from confocal images of $h_{4}$ afferent stained in whole-mount ganglia. We focused on the $\mathrm{h}_{4}$ neuron because its synaptic output to $\mathrm{GI}_{1}$ shows the most robust change (Fig. $3 A$ ). Figure $4 A$ shows the original projection image of a single $\mathrm{h}_{4}$ afferent and its two-dimensional (2D) axogram (representing the 2D branching pattern of the tree). Here we use the value of tree asymmetry to compare the topological structure (branching pattern) between different trees (see Materials and Methods) (Van Pelt et al., 

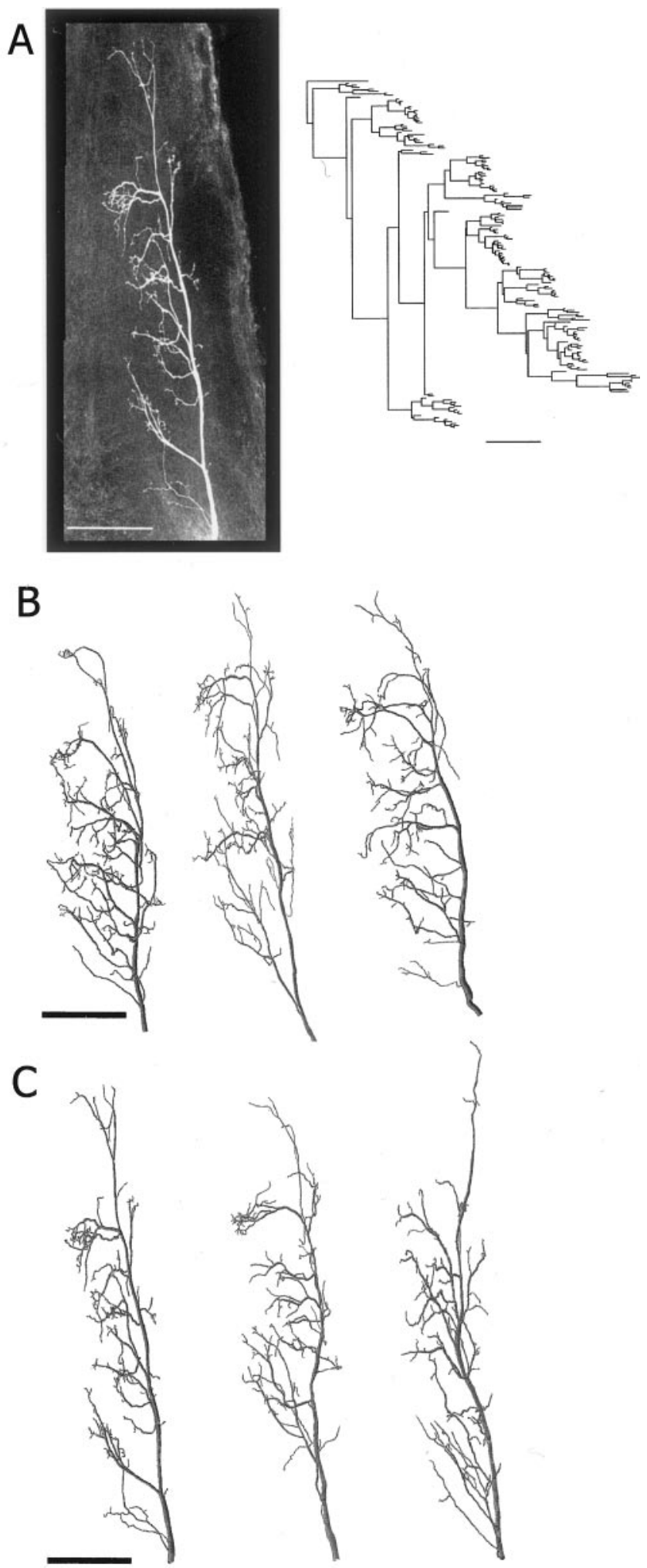

Figure 4. Morphology of presynaptic sensory axons. A, The left photograph is a confocal projection image of an $\mathrm{h}_{4}$ axon terminal (in the dorsal view) stained with neurobiotin-Cy3 in whole mount. The axogram of this neuron is shown as a $2 \mathrm{D}$ representation of the axonal branching pattern on the right. $B$, Three reconstructed examples of $\mathrm{h}_{4}$ axons from control animals. $C$, Three reconstructed examples of $\mathrm{h}_{4}$ axons from $\mathrm{GI}_{2}$-ablated animals (left example is the reconstruction of the afferent shown in $A$ ). Scale bars, $100 \mu \mathrm{m}$.
1992). Three projection images of reconstructed $h_{4}$ sensory axons from the control animals are shown in Figure $4 B$. All neurons have a main primary (lateral) axonal neurite with collaterals extending quite evenly throughout the anterior-posterior axis of the ganglion. Three projection images of reconstructed $h_{4}$ sensory axons from $\mathrm{GI}_{2}$-ablated animals are shown in Figure $4 C$. The general morphology of these two sets of afferents reveals no obvious differences. When quantifying the number of branch points, total length, total surface area, total volume, fractal dimension, and tree asymmetry for these two sets of afferents, we found no significant differences between $\mathrm{h}_{4}$ axons from the control versus $\mathrm{h}_{4}$ axons from the $\mathrm{GI}_{2}$-ablated animals (Table 1$)$ ( $t$ test; $p>0.05$ for all parameters). Thus, there were no gross morphological changes in the axon terminals of the $h_{4}$ afferents after the ablation of one of their postsynaptic target cells $\left(\mathrm{GI}_{2}\right)$.

\section{Postsynaptic dendritic trees of $\mathbf{G I}_{\mathbf{1}}$}

We described the quantitative morphology of $\mathrm{GI}_{1}$ in freshly molted adult animals in Mizrahi et al. (2000). Here we performed a similar morphological analysis on the ipsilateral dendritic tree of $\mathrm{GI}_{1}$ in control and $\mathrm{GI}_{2}$-ablated animals. For reasons of clarity, the dendritic trees are displayed in most cases without the soma, axon, and link segment.

Figure $5 A$ is an example of an original projection image of a neurobiotin-stained $\mathrm{GI}_{1}$ in whole mount (Fig. $5 A$, left) and its $2 \mathrm{D}$ dendrogram (Fig. 5A, right). Three projection images of reconstructed $\mathrm{GI}_{1}$ dendritic trees from the control animals and three reconstructed $\mathrm{GI}_{1}$ dendritic trees from the $\mathrm{GI}_{2}$-ablated animals are shown in Figure 5, $B$ and $C$, respectively. The overall morphology of $\mathrm{GI}_{1}$ does not appear to be affected after removing $\mathrm{GI}_{2}$. This observation was further confirmed by quantitative analysis of branch point number, total length, total surface area, total volume, fractal dimension, and tree asymmetry of these two sets of $\mathrm{GI}_{1}$ dendritic trees. We found no significant morphological differences between dendritic trees of $\mathrm{GI}_{1}$ from the control animals versus dendritic trees of $\mathrm{GI}_{1}$ from the $\mathrm{GI}_{2}$-ablated animals (Table 2) ( $t$ test; $p>0.05$ for all parameters).

In summary, the strengthening of the $\mathrm{h}_{4}$ to $\mathrm{GI}_{1}$ synapse is not correlated with significant changes in the morphology of either the presynaptic terminals $\left(\mathrm{h}_{4}\right)$ or the postsynaptic targets $\left(\mathrm{GI}_{1}\right)$.

\section{Spatial organization of the cercal circuit}

Reorganization of the cercal circuit could occur as a result of changes in the spatial relationship of presynaptic and postsynaptic elements with no changes in the morphometry of these two elements. Indeed, the spatial organization of both the afferent axonal terminals and the dendritic fields of the GIs has important functional consequences for the wind sensitivity of the GIs. In most cases, the receptive field of a given GI can be predicted on the basis of the location of its dendritic field within the afferent map (Jacobs and Theunissen, 1996, 2000). To investigate spatial reorganization of the circuitry, we developed a system that allows us to analyze the spatial relationship between complex dendritic and axonal structures within ganglionic space. At first we constructed a map of the $3 \mathrm{D}$ spatial organization of $\mathrm{GI}_{1}, \mathrm{GI}_{2}$, and $\mathrm{h}_{4}$. Then, we performed a quantitative comparison of the spatial overlap between $\mathrm{GI}_{1}$ and $\mathrm{GI}_{2}$ and between $\mathrm{GI}_{1}$ and $\mathrm{h}_{4}$ both in the control and in the $\mathrm{GI}_{2}$-ablated animals.

The first significant step in generating such a spatial map is to determine the accurate alignment of neurons stained in different preparations. To this aim, we used multiple staining of the GIs from the same ganglion as a basis for alignment (see Materials 
Table 1. Quantitative morphological analysis between axonal trees of $\mathbf{h}_{4}$ sensory afferents in the control and the $\mathbf{G I}_{2}$-ablated $\left(-\mathbf{G I}_{2}\right)$ animals

\begin{tabular}{|c|c|c|c|c|c|c|c|}
\hline & $n$ & $\begin{array}{l}\text { Number } \\
\text { of branch } \\
\text { points }\end{array}$ & $\begin{array}{l}\text { Total length } \\
(\mu \mathrm{m})\end{array}$ & $\begin{array}{l}\text { Total surface } \\
\text { area }\left(\mu \mathrm{m}^{2}\right)\end{array}$ & $\begin{array}{l}\text { Total volume } \\
\left(\mu \mathrm{m}^{3}\right)\end{array}$ & $\begin{array}{l}\text { Fractal } \\
\text { dimension }\end{array}$ & $\begin{array}{l}\text { Tree } \\
\text { asymmetry }\end{array}$ \\
\hline Control & 5 & $155 \pm 29$ & $4332 \pm 654$ & $21,709 \pm 4111$ & $12,500 \pm 2567$ & $1.21 \pm 0.04$ & $0.52 \pm 0.04$ \\
\hline$-\mathrm{GI}_{2}$ & 5 & $149 \pm 32$ & $4699 \pm 1349$ & $24,317 \pm 6725$ & $14,299 \pm 5616$ & $1.23 \pm 0.06$ & $0.52 \pm 0.02$ \\
\hline$t$ test & & ns & ns & ns & ns & ns & ns \\
\hline
\end{tabular}

Each value is the average \pm SD for each parameter. Significance levels are 0.05. ns, Not significant.

and Methods). Figure $6 A$ shows $\mathrm{GI}_{1}, \mathrm{GI}_{2}$, and the $\mathrm{h}_{4}$ afferent (brown, purple, and green, respectively) aligned within the last abdominal ganglion. The primary dendrites of $\mathrm{GI}_{1}$ extend posteriorly from the center of the neuropil, whereas dendrites of $\mathrm{GI}_{2}$ extend in several directions from a more posterior position in the neuropil. The $\mathrm{h}_{4}$ afferent extends from the most posterior to the anterior position of the neuropil. It overlaps en passant, with the thicker dendritic fields of both GIs in the dorsal position of the neuropil. Four enlarged views $\left(0-90^{\circ}\right.$ rotations on the anterior-posterior axis) of the three cells are shown in Figure $6 B$. The branching structure of these trees is complex, which makes the analysis of their spatial relationship rather difficult. To evaluate the possible changes in the spatial organization of these neurons, we used a comparative method for quantitative analysis of tree geometry called the Hausdorff Match method (Mizrahi et al., 2000).

\section{Spatial organization after GI ablation}

We quantified the spatial relationship between $\mathrm{GI}_{1}, \mathrm{GI}_{2}$, and $\mathrm{h}_{4}$ by calculating the one-way HM of several combinations. First, we investigated whether the dendritic tree of $\mathrm{GI}_{1}$ invaded the "vacant territory" previously occupied by $\mathrm{GI}_{2}$. This investigation was performed by comparing the percentage of overlap (HM) of $\mathrm{GI}_{1}$ within $\mathrm{GI}_{2}$ in both control and $\mathrm{GI}_{2}$-ablated animals as illustrated in Figure 7. Dendritic trees of control $\mathrm{GI}_{2}$ (purple) and control $\mathrm{GI}_{1}$ (brown) are presented after alignment to their respective position in the neuropil (Fig. 7A). The inclusion of this $\mathrm{GI}_{1}$ within this $\mathrm{GI}_{2}$ at a tolerance $(\epsilon)$ of $6 \mu \mathrm{m}$ is $39 \%$. This overlap is distributed in different parts of the $\mathrm{GI}_{2}$ tree as shown graphically in the underlying image (Fig. $7 B$ ). On Figure $7 C$, a dendritic tree of control $\mathrm{GI}_{2}$ (purple) and a dendritic tree of $\mathrm{GI}_{1}$ from a $\mathrm{GI}_{2}$-ablated animal (brown) are presented. Notice that because $\mathrm{GI}_{2}$ is actually ablated in this experimental condition, $\mathrm{GI}_{2}$ is representing only the vacant territory. The inclusion of this $\mathrm{GI}_{1}$ within the vacant territory of $\mathrm{GI}_{2}$ at a tolerance $(\epsilon)$ of $6 \mu \mathrm{m}$ is $45 \%$. As in the control animals, this overlap is distributed in different parts of the tree as shown graphically in the underlying image (Fig. $7 D$ ). Figure $7 E$ plots the graphs of the average HM values between $\mathrm{GI}_{2}$ and $\mathrm{GI}_{1}$ in the control and in the $\mathrm{GI}_{2}$-ablated animals. We found no significant differences between these two groups $(n=25$ comparisons from each group; ANCOVA; $p>$ $0.05)$. This suggests that $\mathrm{GI}_{1}$ does not invade the vacant territory of $\mathrm{GI}_{2}$.

Second, we evaluated whether the spatial overlap of the presynaptic axons of $h_{4}$ with the postsynaptic dendritic tree of $\mathrm{GI}_{1}$ changed after ablating $\mathrm{GI}_{2}$. An $\mathrm{h}_{4}$ axonal tree (purple) and a $\mathrm{GI}_{1}$ dendritic tree (brown) from a control and $\mathrm{GI}_{2}$-ablated animals are shown in Figure 8, $A$ and $C$, respectively. Here our analysis distinguishes between two possibilities (presented by the different colors in Fig. 8B,D). First, to determine whether the postsynaptic dendritic trees sprouted toward the presynaptic axonal trees, we
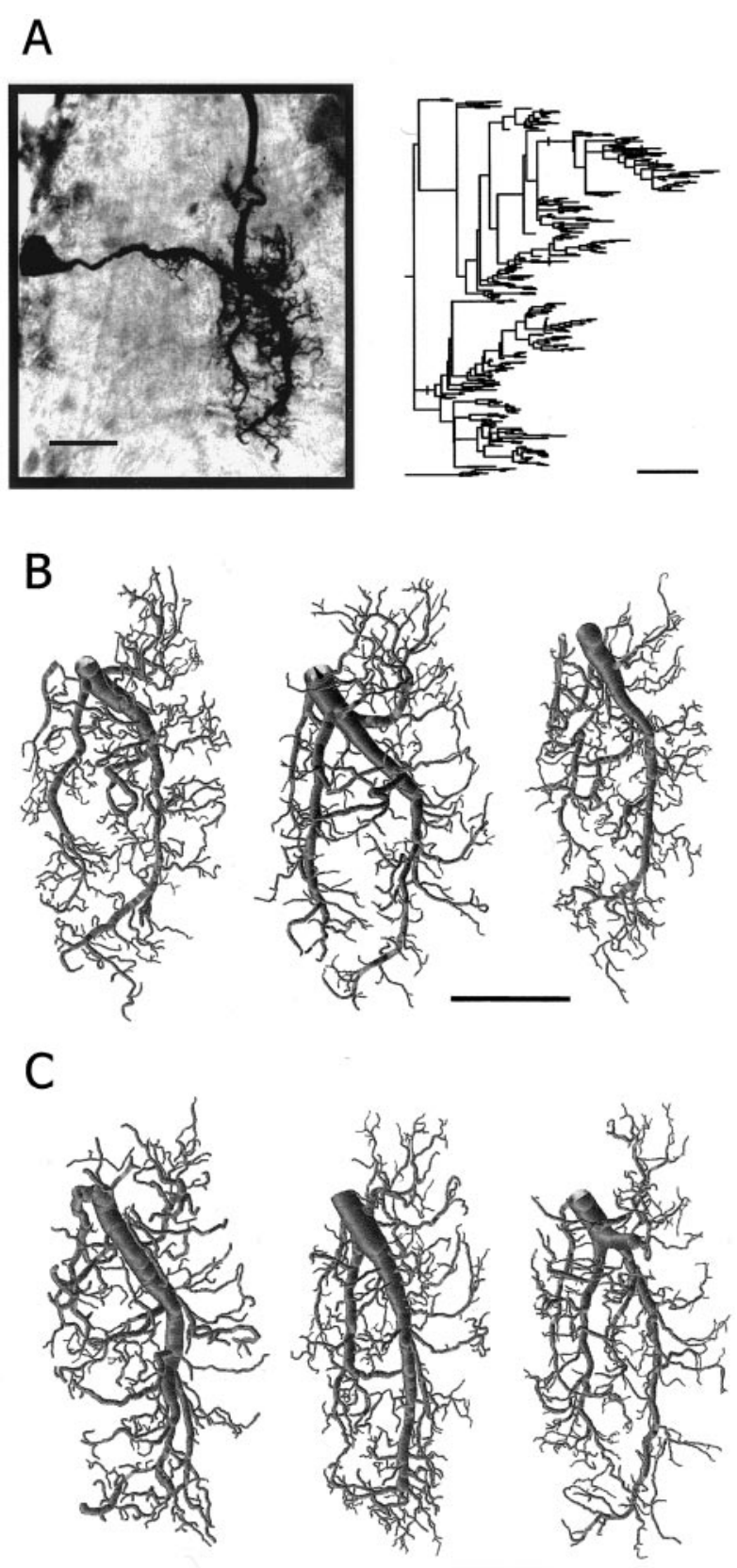

Figure 5. Morphology of postsynaptic dendritic trees. $A$, Photomicrograph of a $\mathrm{GI}_{1}$ (in the dorsal view) stained with neurobiotin-HRP in a whole mount of the ganglion. The dendrogram of this neuron is shown on the right. $B$, Three examples of reconstructed dendritic trees of $\mathrm{GI}_{1}$ from control animals (left example is the reconstruction of the $\mathrm{GI}_{1}$ shown in $A$ ). $C$, Three examples of reconstructed dendritic trees of $\mathrm{GI}_{1}$ from $\mathrm{GI}_{2}$ ablated animals. Scale bars, $100 \mu \mathrm{m}$. 


\begin{tabular}{|c|c|c|c|c|c|c|c|}
\hline & $n$ & $\begin{array}{l}\text { Number of } \\
\text { branch points }\end{array}$ & $\begin{array}{l}\text { Total } \\
\text { length }(\mu \mathrm{m})\end{array}$ & $\begin{array}{l}\text { Total surface } \\
\text { area }\left(\mu \mathrm{m}^{2}\right)\end{array}$ & $\begin{array}{l}\text { Total } \\
\text { volume }\left(\mu \mathrm{m}^{3}\right)\end{array}$ & $\begin{array}{l}\text { Fractal } \\
\text { dimension }\end{array}$ & $\begin{array}{l}\text { Tree } \\
\text { asymmetry }\end{array}$ \\
\hline Control & 5 & $243 \pm 40$ & $8751 \pm 1311$ & $79,506 \pm 13660$ & $105,699 \pm 3310$ & $1.28 \pm 0.03$ & $0.56 \pm 0.01$ \\
\hline$-\mathrm{GI}_{2}$ & 5 & $230 \pm 49$ & $7769 \pm 830$ & $70,116 \pm 8432$ & $91,537 \pm 15,755$ & $1.25 \pm 0.04$ & $0.55 \pm 0.03$ \\
\hline$t$ test & & ns & ns & ns & ns & ns & ns \\
\hline
\end{tabular}

Each value is the average \pm SD for each parameter. Significance levels are 0.05. ns, Not significant.

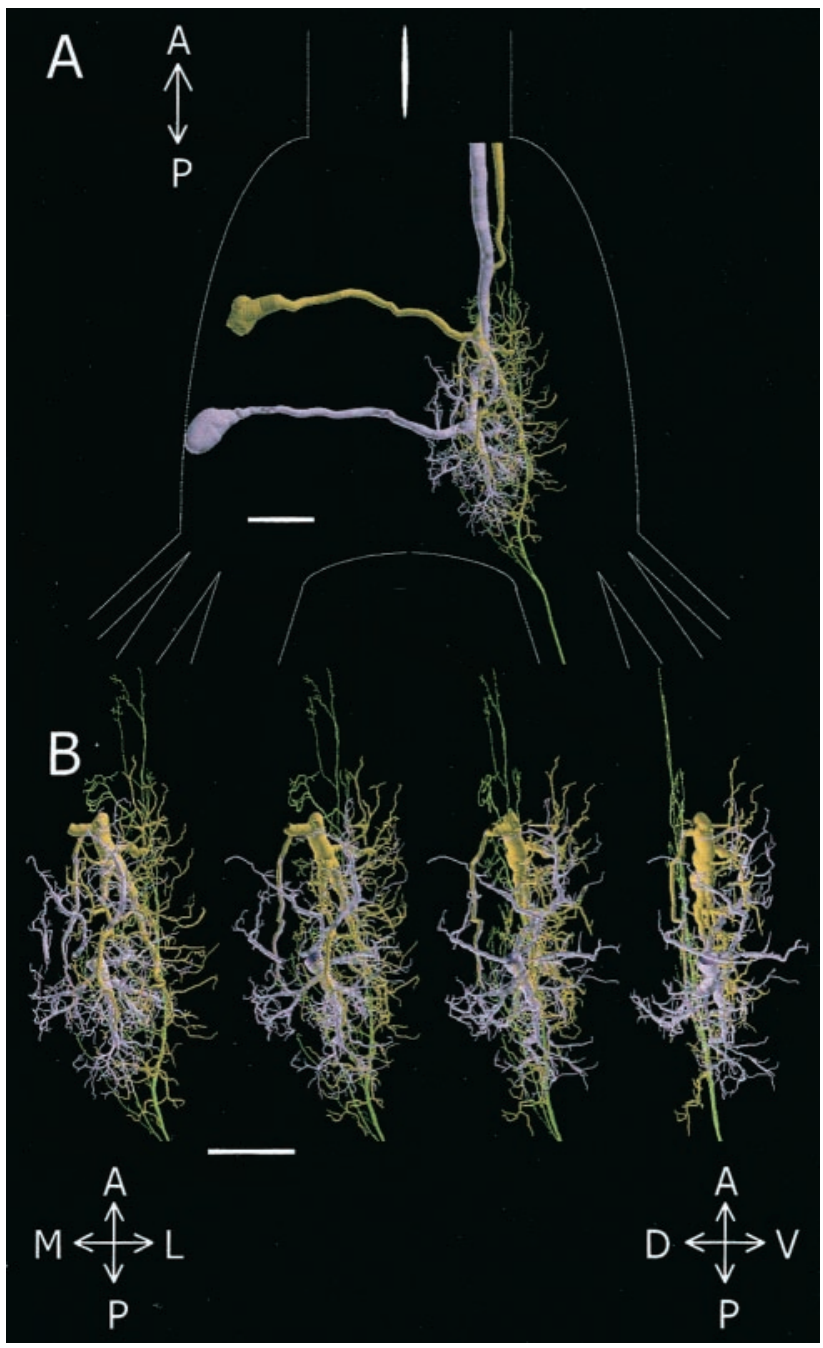

Figure 6. Spatial relationship between the $\mathrm{h}_{4}$ afferent and the dendritic trees of $\mathrm{GI}_{1}$ and $\mathrm{GI}_{2}$. A, Dorsal view of $\mathrm{GI}_{1}$ (brown), $\mathrm{GI}_{2}$ (purple), and $\mathrm{h}_{4}$ (green) aligned within the last abdominal ganglion, the outlines of which are shown in white. $B$, Magnified view of the dendrites and axon shown in $A$ for four different rotations around the anterior-posterior axis. Scale bars, $100 \mu \mathrm{m}$. $A$, Anterior; $P$, posterior; $M$, medial; $L$, lateral; $V$, ventral; $D$, dorsal.

calculated the HM between $\mathrm{GI}_{1}$ and $\mathrm{h}_{4}$ in the control versus the $\mathrm{GI}_{2}$-ablated animals (Fig. $8 E$ ). We found no significant differences between control and $\mathrm{GI}_{2}$-ablated pairs $(n=25$ comparisons from five animals for each group; ANCOVA; $p>0.05)$. Two illustrations of these comparisons are shown by the brown dots in Figure 8, $B$ and $D$, corresponding to dendritic trees in Figure 8, $A$ and $C$, respectively. Second, to determine whether the presynaptic axonal trees sprouted toward the postsynaptic dendritic trees, we calculated the $\mathrm{HM}$ between $\mathrm{h}_{4}$ and $\mathrm{GI}_{1}$ in the control versus the $\mathrm{GI}_{2}$-ablated animals (Fig. $8 F$ ). We found no significant differences between the control and the $\mathrm{GI}_{2}$-ablated pairs $(n=25$ comparisons from five animals for each group; ANCOVA; $p>$ $0.05)$. These comparisons are illustrated graphically by the purple dots in Figure 8, $B$ and $D$, corresponding to axonal trees in Figure $8, A$ and $C$, respectively. The spatial overlap showed similar patterns in both the control and the $\mathrm{GI}_{2}$-ablated animals (data not shown). Therefore, there seems to be no stereotyped spatial reorganization between $\mathrm{h}_{4}$ and $\mathrm{GI}_{1}$ after ablation of $\mathrm{GI}_{2}$.

\section{DISCUSSION}

\section{Regulation of synaptic connectivity}

After the ablation of a postsynaptic cell in the cercal circuit the connections made by its presynaptic inputs are altered. This reorganization is expressed as changes in the strength of specific synapses but not as changes in the morphology of the presynaptic and postsynaptic elements. This suggests that postsynaptic elements play a role in the maintenance of the synaptic circuitry by means of mechanisms that do not involve modifications of neuronal architecture.

In this experiment we tested $\mathrm{GI}_{1}$ after ablating either $\mathrm{GI}_{2}$ or $\mathrm{GI}_{3}$. Normally, $\mathrm{GI}_{2}$ and $\mathrm{GI}_{3}$ receive input from 11 and 9 sensory columns, respectively. Therefore, ablation of $\mathrm{GI}_{2}$ and $\mathrm{GI}_{3}$ deprived several dozens of sensory neurons of their target. $\mathrm{GI}_{1}$ receives input from at least 11 columns (Hamon et al., 1994) and thus shares with $\mathrm{GI}_{2}$ or $\mathrm{GI}_{3}$ the input from at least 9 columns. In the present study, we only analyzed the changes in the synaptic strength for two columns ( $h$ and d), and it is not unlikely that the synaptic strength of other columns that we did not sample were affected as well.

One mechanism for regulating synaptic strength is retrograde signaling from postsynaptic neurons to presynaptic terminals as has been shown for peripheral synapses (Davis and Goodman, 1998; Davis, 2000). At the Drosophila neuromuscular junction, a reduction in the number of glutamate receptors on the postsynaptic muscle cells induces an increase in presynaptic transmitter release (Petersen et al., 1997). Likewise, at the mouse neuromuscular junction, a decrease in acetylcholine receptors on the postsynaptic muscle cells results in an increase in transmitter release (Sandrock et al., 1997). Interestingly, this mechanism was also suggested to be operative at a central synapse, the sensoryto-giant interneuron synapse of the cricket cercal system. There, retrograde signaling of postsynaptic giant interneurons regulates transmitter release of sensory neurons (Davis and Murphey, 1993).

With this in mind, we speculate that the ablation of a postsynaptic giant interneuron removes a retrograde signal that is detected by the presynaptic terminals. This could induce an increase in transmitter release at the remaining release sites on other giant interneurons. Furthermore, the reorganization that we observed appears to be correlated with the strength of a given synapse. For instance, in the control animals the $\mathrm{h}$ to $\mathrm{GI}_{2}$ synapse is stronger 


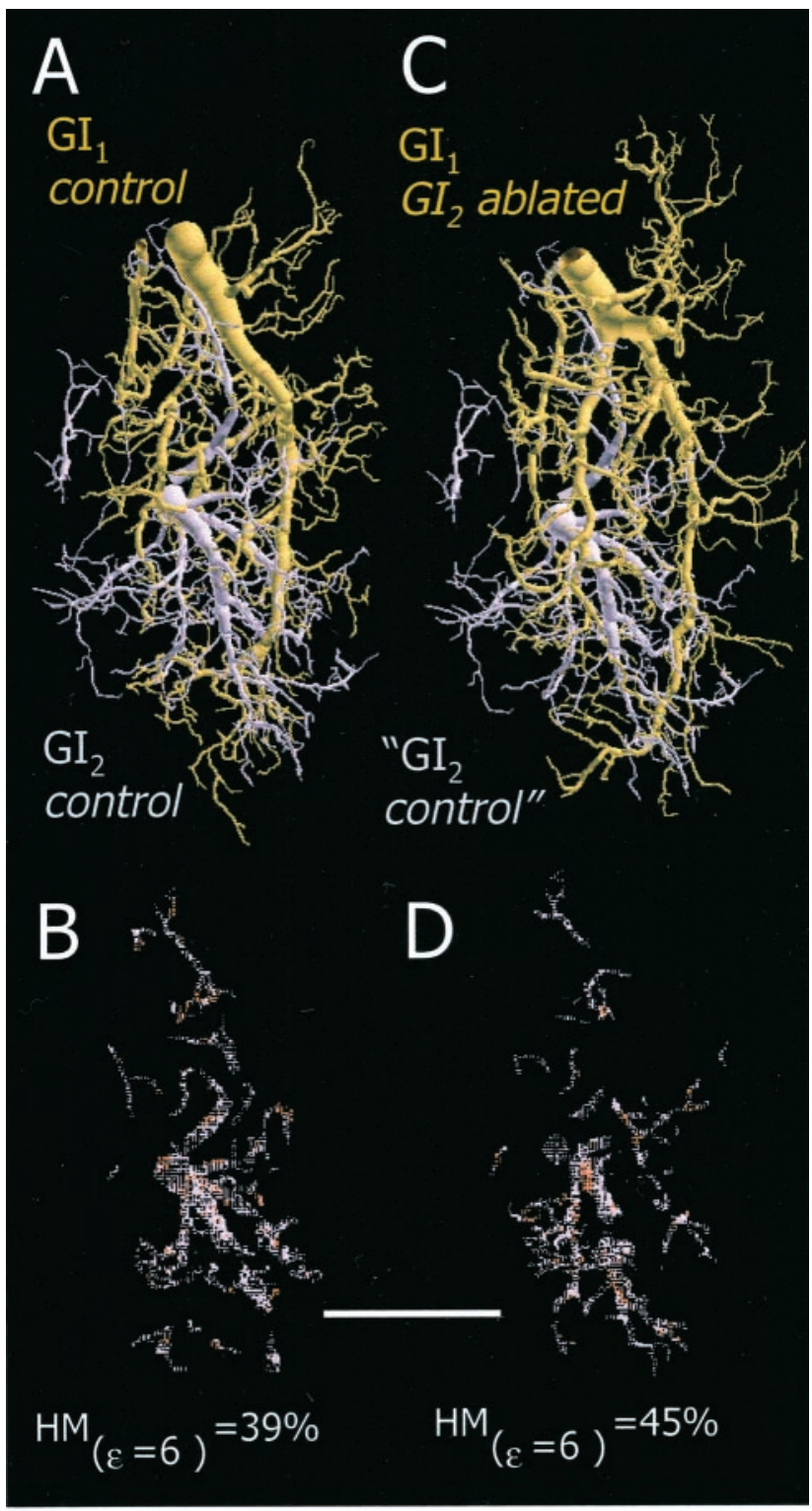

$\mathrm{E}$

$$
\begin{aligned}
& -\mathrm{GI}_{2} \text { (cont.) vs. } \mathrm{GI}_{1} \text { (cont.) } \\
& \mathrm{GI}_{2} \text { (cont.) vs. } \mathrm{GI}_{1}\left(\mathrm{GI}_{2}\right. \text { ablated) }
\end{aligned}
$$

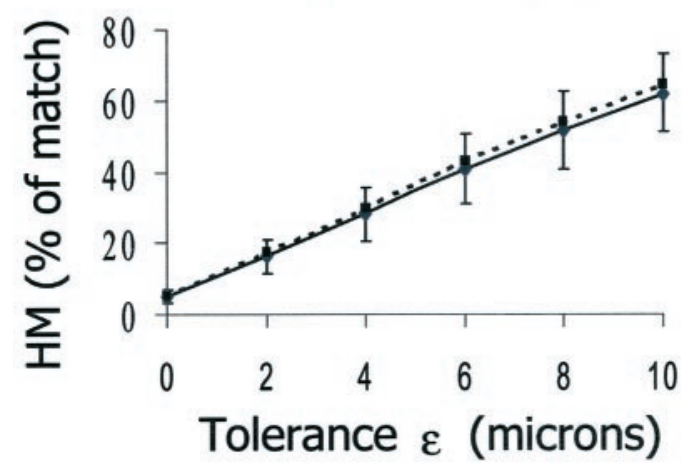

Figure 7. Spatial analysis of the overlap between $\mathrm{GI}_{1}$ and $\mathrm{GI}_{2}$ in control and experimental animals. $A$, Two dendritic trees from a control animal $\left(\mathrm{GI}_{1}\right.$, brown; $\mathrm{GI}_{2}$, purple) are shown aligned to their respective positions in ganglionic space. $B$, Spatial representation of the dendritic fields of $\mathrm{GI}_{2}$ overlapping with $\mathrm{GI}_{1}$ at $\epsilon=6 \mu \mathrm{m}$. Here, $39 \%$ of the dendritic tree of $\mathrm{GI}_{2}$ overlaps with that of $\mathrm{GI}_{1}$. $C$, Dendritic tree of $\mathrm{GI}_{1}$ from a $\mathrm{GI}_{2}$-ablated than the d to $\mathrm{GI}_{2}$ synapse (Daley and Camhi, 1988; Hamon et al., 1994). After $\mathrm{GI}_{2}$ ablation, the changes measured at the $\mathrm{h}$ to $\mathrm{GI}_{1}$ synapse were larger than at the $\mathrm{d}$ to $\mathrm{GI}_{1}$ synapse. Consistent with our hypothesis, the $\mathrm{h}$ afferents do not synapse onto $\mathrm{GI}_{3}$ (Hamon et al., 1994), and the $\mathrm{h}$ to $\mathrm{GI}_{1}$ synapse was not affected after $\mathrm{GI}_{3}$ was ablated. Therefore, the presence of a postsynaptic target is required for synaptic reorganization. In fact, it has been suggested that a neuron has a constant number of terminal branches that it autoregulates (Devor and Schneider, 1975; Smalheiser and Crain, 1984). In the neuromuscular junction, Gan and Macagno (1995) have provided support for this idea by showing that removal of specific terminal branches in an identified mechanosensory neuron induces sprouting of new branches at a site distant from the lesion. This indicates that a given neuron has a limited capacity to produce terminal branches; each is generated at the expense of others.

Which plausible mechanism could account for the increase in the $\mathrm{h}$ to $\mathrm{GI}_{1}$ synapse and a parallel decrease in the $\mathrm{d}$ to $\mathrm{GI}_{1}$ synapse? Because the $\mathrm{h}$ to $\mathrm{GI}_{2}$ synapse is stronger than the $\mathrm{d}$ to $\mathrm{GI}_{2}$ synapse, after ablation of $\mathrm{GI}_{2}$, both $\mathrm{h}$ and d could compete for access to $\mathrm{GI}_{1}$. Competition between cercal afferents has been demonstrated in the cercal system of the first instar cockroach. In this system, only two sensory hairs that each code for front or back wind provide input to $\mathrm{GI}_{1}, \mathrm{GI}_{2}$, and $\mathrm{GI}_{3}$ (Camhi, 1984). In mutant animals, an extrasensory hair competes with the other two hairs, thereby decreasing their synaptic drive on the postsynaptic GIs (Bacon and Blagburn, 1992). Moreover, the total synaptic drive to a GI remains the same in the presence of additional input from the extra hair. This suggests that the postsynaptic GI can accept only a limited number of synapses. Given these facts, we propose that after $\mathrm{GI}_{2}$ ablation, the $\mathrm{h}$ and $\mathrm{d}$ afferents enter a contest for access to $\mathrm{GI}_{1}$ in which $\mathrm{h}$ wins over $\mathrm{d}$. This competition may involve a regulation of the absolute number of inputs from $h$ and $\mathrm{d}$ afferents by $\mathrm{GI}_{1}$.

Another possible mechanism of regulating synaptic strength is presynaptic afferent activity (Turrigiano, 1999; Zucker, 1999). Could changes in presynaptic activity account for the synaptic reorganization observed in the cercal system? We regard this possibility as unlikely for two reasons. First, GIs do not interact synaptically, and therefore ablation of a GI should have little direct effect on the response of other GIs (Mizrahi and Libersat, 1997). Second, in the cricket cercal system, blockage of presynaptic activity affects neither synaptic reorganization observed during normal postembryonic development nor regeneration of presynaptic terminals after deafferentation (Chiba and Murphey, 1990).

\section{Does the synaptic reorganization of the cercal circuit have consequences for the escape behavior?}

Because our study did not address the behavioral consequence of the synaptic reorganization after single GI photoablation, we can only speculate about the impact of such reorganization with

animal (brown) and a dendritic tree of $\mathrm{GI}_{2}$ from a control animal ( purple). Because $\mathrm{GI}_{2}$ is actually missing in this experimental situation, the $\mathrm{GI}_{2}$ is representing only the vacant territory. $D$, Spatial representation of the dendritic fields of $\mathrm{GI}_{2}$ overlapping with $\mathrm{GI}_{1}$ at $\epsilon=6 \mu \mathrm{m}$. Here, $45 \%$ of the dendritic tree of $\mathrm{GI}_{2}$ overlaps with that of $\mathrm{GI}_{1}$. Scale bar, $100 \mu \mathrm{m}$. $E$, Graph of the average $\mathrm{HM}$ values between $\mathrm{GI}_{1}$ and $\mathrm{GI}_{2}$ in the control animals ( $n=25$ comparisons from 5 animals; solid line) and between $\mathrm{GI}_{2}$ from the control animals and $\mathrm{GI}_{1}$ from the $\mathrm{GI}_{2}$-ablated animals $(n=25$ comparisons from 5 animals; dotted line $)$. We found no significant differences between the two groups (ANCOVA; $p>0.05$ ). 

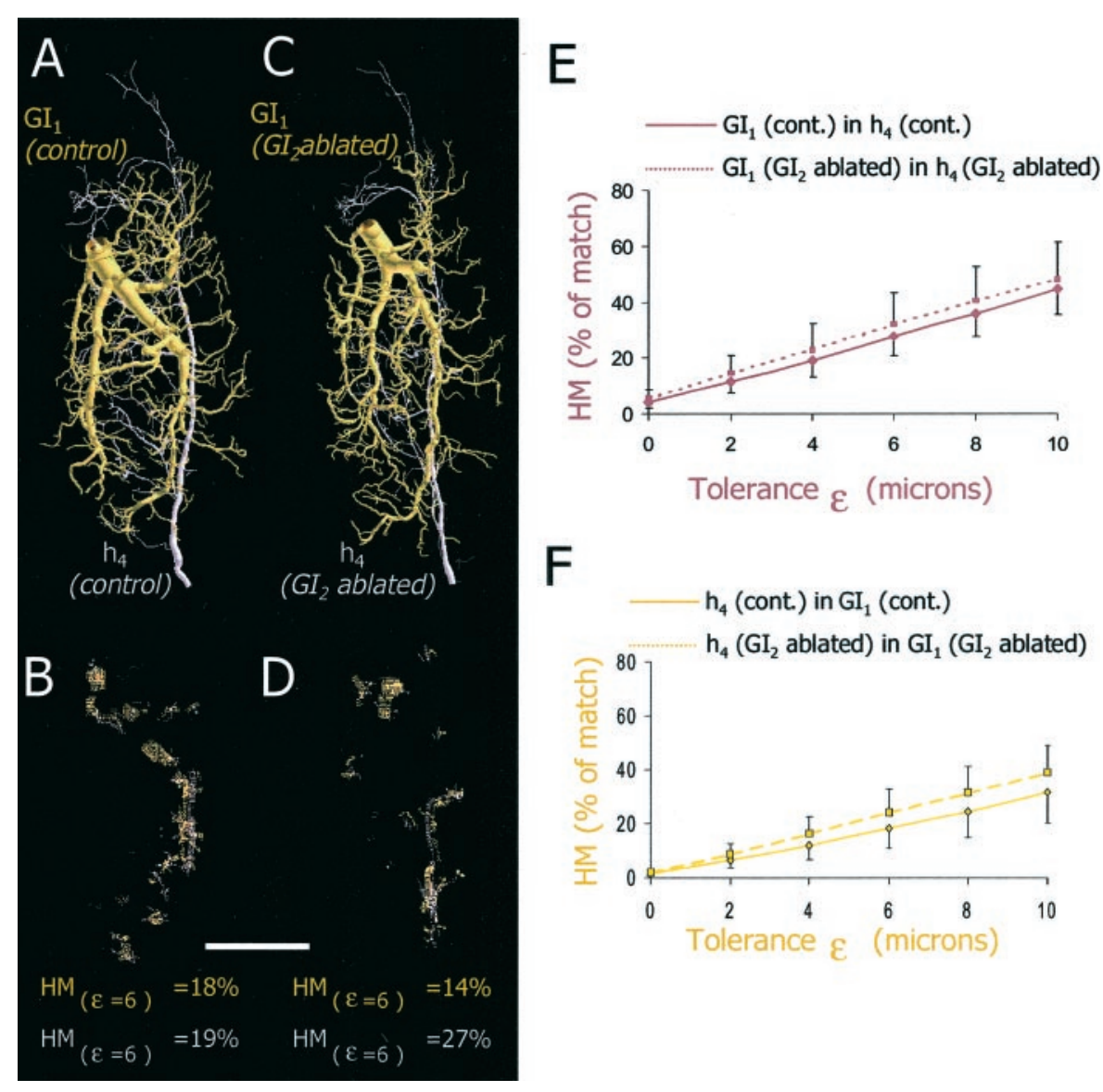

Figure 8. Spatial analysis of the overlap between presynaptic axonal trees of $\mathrm{h}_{4}$ and postsynaptic dendritic trees of $\mathrm{GI}_{1} . A, \mathrm{~A}$ dendritic tree of $\mathrm{GI}_{1}$ (brown) and an axonal tree of $\mathrm{h}_{4}$ (purple) from control animals are shown aligned to their respective positions in the ganglion. $B$, Spatial representations of the dendritic areas of $\mathrm{GI}_{1}$ that overlap with $\mathrm{h}_{4}$ (brown dots) and the axonal areas of $\mathrm{h}_{4}$ that overlap with $\mathrm{GI}_{1}$ (purple dots) at $\epsilon=6$ $\mu \mathrm{m}$ (18 and $19 \%$, respectively). $C$, A dendritic tree of $\mathrm{GI}_{1}$ (brown) and an axonal tree of $\mathrm{h}_{4}$ ( purple) from $\mathrm{GI}_{2}$-ablated animals are shown spatially aligned. $D$, Spatial representations of the overlap between dendritic trees of $\mathrm{GI}_{1}$ and axonal trees of $\mathrm{h}_{4}$ in the $\mathrm{GI}_{2}$-ablated animals shown at $\epsilon=6 \mu \mathrm{m}$ (14 and $27 \%$, respectively). Scale bar, $100 \mu \mathrm{m}$. E, Graph of the one-way HM of $\mathrm{GI}_{1}$ in $\mathrm{h}_{4}$ from control animals $(n=25$ comparisons from 5 animals for each group; solid line) and of $\mathrm{GI}_{1}$ in $\mathrm{h}_{4}$ from $\mathrm{GI}_{2}$-ablated animals ( $n=25$ comparisons from 5 animals; dotted line $)$. We found no significant differences between the two groups (ANCOVA; $p>0.05$ ). $F$, Graph of the one-way $\mathrm{HM}$ of $\mathrm{h}_{4}$ in $\mathrm{GI}_{1}$ from control animals ( $n=25$ comparisons from 5 animals; solid line) and of $\mathrm{h}_{4}$ in $\mathrm{GI}_{1}$ from $\mathrm{GI}_{2}$-ablated animals $(n=25$ comparisons from 5 animals for each group; dotted line). We found no significant differences between the two groups (ANCOVA; $p>0.05)$.

respect to the directionality of escape behavior. It has been shown that removing a GI has a direct effect on the directionality of the escape behavior of animals tested up to $1 \mathrm{~d}$ after the lesion (Comer, 1985; Levi and Camhi, 2000). Conversely, adding action potentials to a single GI by intracellular current injection affects the turning tendency of the cockroach in a predictable way. However, in these studies, the long-term effects of GI ablation have not been examined. Thus, it is possible that after 1 month, the synaptic reorganization results in an improvement or recovery in the directionality of the escape behavior of the animal. Such is the case when one removes one cercus and examines the escape behavior of cockroaches $1 \mathrm{~d}$ and 1 month after the lesion (Vardi and Camhi, 1982a). The functional recovery of the escape system is caused by an increase in the strength of the input from the intact cercus (Volman, 1989). It is expressed as an enhancement of the wind sensitivity of the deafferented GIs (Vardi and Camhi, 1982b).

Interestingly, the specificity of the changes in synaptic rewiring of the cercal to GIs circuit is consistent with a functional compensation of the escape circuit. Thus, after ablation of $\mathrm{GI}_{2}$ (a back wind neuron) the back wind detectors (e.g., column h neurons) increase their synaptic strength onto $\mathrm{GI}_{1}$, and the front wind detectors (e.g., column d neurons) decrease their synaptic strength on $\mathrm{GI}_{1}$. This parallel increase in back wind input and decrease in front wind input is expected to shift the wind receptive field of $\mathrm{GI}_{1}$ toward back wind and may compensate for the lost $\mathrm{GI}_{2}$.

\section{Morphological correlates of synaptic plasticity}

The architecture of axonal presynaptic and dendritic postsynaptic neurites is critical in the establishment of proper connectivity and biophysical properties in a network. One cellular mechanism that restricts dendrites to grow into their specific territories is "dendritic competition." In the developing rat retina, the dendrites of ganglion cells shift toward an area of the retina depleted from neighboring ganglion cells (Perry and Linden, 1982). This suggests that dendritic growth is regulated in part by interactions with neighboring dendrites. In a recent study, Gao et al. (2000) analyzed factors that affect the morphology of sensory multiple dendrite neurons in the nervous system of the Drosophila larvae. Using photoablation, they provided evidence for dendritic competition between dendritic trees of homologous neurons from different segments but not from the same segment. A G-proteincoupled receptor called flamingo seems to be required for the competitive interaction between dendrites. In the present study, we show that although $\mathrm{GI}_{1}$ and $\mathrm{GI}_{2}$ share space and input, the morphology of $\mathrm{GI}_{1}$ remains stable after ablating $\mathrm{GI}_{2}$. Thus, our results concerning the cercal system suggest that dendritic trees do not compete for space and input. However, it is worth noting that we removed a dendritic tree from a fully developed nervous system, whereas the studies mentioned above (Perry and Linden, 1982; Gao et al. 2000) examined the consequences of removing a dendritic tree from a developing nervous system. Indeed, the phenomenon of dendritic competition in the retina is age dependent and does not occur when lesions are made in 20-d-old rats (Perry and Maffei, 1988). Nevertheless, our results on synaptic physiology show that ablation of one dendritic tree indirectly affects synaptic strength on other trees. In that respect, it would be interesting to examine the physiological consequences of dendritic manipulation in the rat retinal circuit and in the nervous system of the Drosophila larvae. 
Our results show that, at the resolution of our imaging system, there are no structural changes associated with increased synaptic strength of the $h_{4}$ afferent on $\mathrm{GI}_{1}$. The number of synaptic contacts between the sensory terminal branches and the dendrites of the remaining GIs may have changed. To evaluate such possible changes in synaptic contacts between the $\mathrm{h}$ afferent and the $\mathrm{d}$ afferent with $\mathrm{GI}_{1}$, an electron microscopy investigation is required. It is also possible that competitive interactions would have been expressed as noticeable morphological changes if we had increased the number of ablated neurons in the cercal circuit. However, we found that the success of recovery of the operated animals depends strongly on the duration of the surgical procedure, which is limited by the photoablation procedure. This technical difficulty prevented us from testing the effect of removing several GIs on the morphology of the remaining GIs. In addition, we cannot rule out the possibility that the morphology of other wind-sensitive neurons has been altered by GI ablation. However, we have little, if any, information regarding the spatial overlap and the nature of shared input between these neurons and the GIs.

Competitive interactions between neurons has been studied extensively in a number of invertebrate and vertebrate systems. However, the number of neurons involved in these competitive interactions is often large, and accurate measurements of the synaptic and concomitant structural changes in these large circuits is often difficult. The cercal system, which comprises a limited number of identified presynaptic and postsynaptic identified elements, remains one of the most suitable systems to examine competition and reorganization at central synapses.

\section{REFERENCES}

Bacon JP, Blagburn JM (1992) Ectopic sensory neurons in mutant cockroaches compete with normal cells for central targets. Development 115:773-784

Camhi JM (1984) Neuroethology. Sunderland, MA: Sinauer.

Camhi JM (1989) The code for stimulus direction in a cell assembly in the cockroach. J Comp Physiol [A] 165:83-97.

Chiba A, Murphey RK (1990) Connectivity of identified central synapses in the cricket is normal after regeneration and blockade of presynaptic activity. J Neurobiol 22:130-142.

Comer CM (1985) Analyzing cockroach escape behavior with lesions of individual giant interneurons. Brain Res 335:342-346.

Comer CM, Dowd JP, Stubblefield GT (1988) Escape response following elimination of the giant interneuron pathway in the cockroach, Periplaneta americana. Brain Res 445:370-375.

Daley DL, Camhi JM (1988) Connectivity pattern of the cercal-to-giant interneuron system of the American cockroach. J Neurophysiol 60:1350-1367.

Daley DL, Vardi N, Appignani B, Camhi JM (1981) Morphology of the giant interneurons and cercal nerve projections of the American cockroach. J Comp Neurol 196:41-52.

Davis GW (2000) The making of a synapse: target-derived signals and presynaptic differentiation. Neuron 26:551-554.

Davis GW, Goodman CS (1998) Genetic analysis of synaptic development and plasticity: homeostatic regulation of synaptic efficacy. Curr Opin Neurobiol 8:149-156.

Davis GW, Murphey RK (1993) A role for postsynaptic neurons in determining presynaptic release properties in the cricket CNS: evidence for retrograde control of facilitation. J Neurosci 13:3827-3838.

Devor M, Schneider G (1975) Neuroanatomical plasticity: the principle of conservation of total axonal arborisation. In: Aspects of neural plasticity (Vital-Durand F, Jeannerod M, eds), pp 191-200. Paris: INSERM Colloquia.

Gan WB, Macagno ER (1995) Interactions between segmental homologs and between isoneuronal branches guide the formation of sensory terminal fields. J Neurosci 15:3243-3253.

Gan WB, Macagno ER (1997) Competition among the axonal projections of an identified neuron contributes to the retraction of some of those projections. J Neurosci 17:4293-4301.
Gao FB, Kohwi M, Brenman JE, Jan LY, Jan YN (2000) Control of dendritic field formation in Drosophila: the roles of flamingo and competition between homologous neurons. Neuron 28:91-101.

Guillery RW (1988) Competition in the development of the visual pathways. In: The making of the nervous system (Parnavelas JG, Stern CD, Stirling RV, eds), pp 356-379. New York: Oxford UP.

Hamon A, Guillet JC, Callec JJ (1988) Initiation and conduction of impulses in mechanosensory neurons: effects of hypoxia. Comp Biochem Physiol 91A:797-805.

Hamon A, Guillet JC, Callec JJ (1994) Patterns of monosynaptic input to the giant interneurons $1-3$ in the cercal system of the adult cockroach. J Comp Physiol 174:91-102.

Horner PJ, Gage FH (2000) Regenerating the damaged central nervous system. Nature 407:963-970.

Jacobs GA, Nevin R (1991) Anatomical relationships between sensory afferent arborizations in the cricket cercal system. Anat Rec 231:563-572.

Jacobs GA, Theunissen FE (1996) Functional organization of a neural map in the cricket cercal sensory system. J Neurosci 16:769-784.

Jacobs GA, Theunissen FE (2000) Extraction of sensory parameters from a neural map by primary sensory interneurons. J Neurosci 20:2934-2943.

Kempermann G, Kuhn HG, Gage FH (1997) More hippocampal neurons in adult mice living in an enriched environment. Nature 386:493-495.

Kolton L, Camhi JM (1995) Cartesian representation of stimulus direction: parallel processing by two sets of giant interneurons in the cockroach. J Comp Physiol [A] 176:691-702.

Levi R, Camhi JM (2000) Population vector coding by the giant interneurons of the cockroach. J Neurosci 20:3822-3829.

Libersat A (1989) Photoinactivation of a portion of a neurone for longterm studies of its role in behaviour. J Exp Biol 142:453-459.

Libersat F, Mizrahi A (1996) In situ visualization and photoablation of individual neurons using a low cost fiber optic system. J Neurosci Methods 67:157-162.

Martin SJ, Grimwood PD, Morris RG (2000) Synaptic plasticity and memory: an evaluation of the hypothesis. Annu Rev Neurosci 23:649-711

Miller JP, Selverston AI (1979) Rapid killing of single neurons by irradiation of intracellularly injected dye. Science 206:702-704.

Mizrahi A, Libersat F (1997) Independent coding of wind direction in cockroach giant interneurons. J Neurophysiol 78:2655-2661.

Mizrahi A, Libersat F (2000) Do dendritic arbors compete for input: a 3-D morphometric analysis. Neurosci Lett [Suppl] 55:37.

Mizrahi A, Ben-ner E, Glusman JG, Katz M, Kedem K, Libersat F (2000) Comparative analysis of dendritic architecture of identified neurons using the Hausdorff distance metric. J Comp Neurol 422:415-428.

Muller KJ, Gu XN (1991) Unequal competition between axons for neuronal targets. Philos Trans R Soc Lond B Biol Sci 331:315-322.

Murphey RK, Lemere CA (1984) Competition controls the growth of an identified axonal arborization. Science 224:1352-1355.

Nguyen QT, Lichtman JW (1996) Mechanism of synapse disassembly at the developing neuromuscular junction. Curr Opin Neurobiol 6:104-112.

Nilsson M, Perfilieva E, Johansson U, Orwar O, Eriksson PS (1999) Enriched environment increases neurogenesis in the adult rat dentate gyrus and improves spatial memory. J Neurobiol 39:569-578.

Penn AA, Riquelme PA, Feller MB, Shatz CJ (1998) Competition in retinogeniculate patterning driven by spontaneous activity. Science 279:2108-2112.

Perry VH, Linden R (1982) Evidence for dendritic competition in the developing retina. Science 297:683-685.

Perry VH, Maffei L (1988) Dendritic competition: competition for what? Dev Brain Res 41:195-208.

Petersen SA, Fetter RD, Noordermeer JN, Goodman CS, DiAntonio A (1997) Genetic analysis of glutamate receptors in Drosophila reveals a retrograde signal regulating presynaptic transmitter release. Neuron 19:1237-1248.

Ritzmann RE (1984) The cockroach escape response. In: Neural mechanisms of startle behavior (Eaton R, ed), pp 93-131. New York: Plenum.

Sandrock AW, Dryer SE, Rosen KM, Gozani SN, Kramer R, Theill LE, Fischbach GD (1997) Maintenance of acetylcholine receptor number by neuregulins at the neuromuscular junction in vivo. Science 276:599-604.

Smalheiser NR, Crain SM (1984) The possible role of "sibling neurite bias" in the coordination of neurite extension, branching, and survival. J Neurobiol 15:517-529.

Stern M, Ediger VL, Gibbon CR, Blagburn JM, Bacon JP (1997) Regeneration of cercal filiform hair sensory neurons in the first-instar cockroach restores escape behavior. J Neurobiol 33:439-458. 
Turrigiano GG (1999) Homeostatic plasticity in neuronal networks: the more things change, the more they stay the same. Trends Neurosci 22:221-228.

Van Pelt J, Uylings HB, Verwer RW, Pentney RJ, Woldenberg MJ (1992) Tree asymmetry - a sensitive and practical measure for binary topological trees. Bull Math Biol 54:759-784.

Vardi N, Camhi JM (1982a) Functional recovery from lesions in the escape system of the cockroach. I. Behavioral recovery. J Comp Physiol [A] 146:291-298.

Vardi N, Camhi JM (1982b) Functional recovery from lesions in the escape system of the cockroach. II. Physiological recovery of the giant interneurons. J Comp Physiol [A] 146:299-309.
Volman SF (1989) Localization of the enhanced input to cockroach giant interneurons after partial deafferentation. J Neurobiol 20:762-783.

Volman SF, Camhi JM (1988) The role of afferent activity in behavioral and neuronal plasticity in an insect. J Comp Physiol [A] 162:781-791. Wiesel TN, Hubel DH (1963) Single cell responses in striate cortex of kittens deprived of vision in one eye. J Neurophysiol 26:1003-1017.

Young D, Lawlor PA, Leone P, Dragunow M, During MJ (1999) Environmental enrichment inhibits spontaneous apoptosis, prevents seizures and is neuroprotective. Nat Med 4:448-453.

Zucker RS (1999) Calcium- and activity-dependent synaptic plasticity. Curr Opin Neurobiol 3:305-313. 